\title{
PPARa ligand, AVE8134, and cyclooxygenase inhibitor therapy synergistically suppress lung cancer growth and metastasis
}

\author{
Lujin Wu ${ }^{1,2}$, Wei Wang ${ }^{1,2}$, Meiyan Dai ${ }^{1,2}$, Huihui $\mathrm{Li}^{1,2}$, Chen Chen ${ }^{1,2}$ and Daowen Wang ${ }^{1,2^{*}}$
}

\begin{abstract}
Background: Lung cancer $(\mathrm{LC})$ is one of the leading causes of death worldwide, which highlights the urgent need for better therapies. Peroxisome proliferator-activated nuclear receptor alpha (PPARa), known as a key nuclear transcription factor involved in glucose and lipid metabolism, has been also implicated in endothelial proliferation and angiogenesis. However, the effects and potential mechanisms of the novel PPARa ligand, AVE8134, on LC growth and progression remain unclear.
\end{abstract}

Methods: A subcutaneous tumour was established in mice by injecting TC-1 lung tumour cells $\left(\sim 1 \times 10^{6}\right.$ cells $)$ into their shaved left flank. These mice were treated with three different PPARa ligands: AVE8134 (0.025\% in drinking water), Wyeth-14,643 (0.025\%), or Bezafibrate (0.3\%). Tumour sizes and metastasis between treated and untreated mice were then compared by morphology and histology, and the metabolites of arachidonic acid (AA) were detected by liquid chromatography-tandem mass spectrometry (LC-MS/MS). Inhibition of either Cyp2c44 expression by genetic disruption or cyclooxygenase (COX) activity by indomethacin was used to test the mechanisms by which AVE8134 affects tumour growth.

Results: The pharmacodynamics effects of AVE8134, Wyeth-14,643, and Bezafibrate on lipids control were similar. However, their effects on tumour suppression were different. Eicosanoid profile analysis showed that all PPARa ligands reduced the production of AA-derived epoxyeicosatrienoic acids (EETs) and increased the hydroxyl product, 11-hydroxyeicosatetraenoic acids (11-HETE). Moreover, increased 11-HETE promoted endothelial proliferation, angiogenesis, and subsequent tumour deterioration in a dose-dependent manner possibly via activating the AKT/ extracellular signal-regulated kinase (ERK) pathway. The increased 11-HETE partly neutralized the benefits provided by the Cyp2c44-EETs system inhibited by PPARa ligands in tumour-bearing mice. AVE8134 treatment worsened the tumour phenotype in Cyp2c44 knockout mice, indicating that AVE8134 has contradictory effects on tumour growth. The COX inhibitor indomethacin strengthened the inhibitory actions of AVE8134 on tumour growth and metastasis by inhibiting the 11-HETE production in vivo and in vitro.

Conclusion: In this study, we found that the degrees of inhibition on LC growth and metastasis by PPARa ligands depended on their bidirectional regulation on EETs and 11-HETE. Considering their safety and efficacy, the novel PPARa ligand, AVE8134, is a potentially ideal anti-angiogenesis drug for cancer treatment when jointly applied with the COX inhibitor indomethacin.

Keywords: PPARa agonist, AVE8134, Lung cancer, Indomethacin, EETs, 11-HETE

\footnotetext{
* Correspondence: dwwang@tjh.tjmu.edu.cn

'Division of Cardiology, Department of Internal Medicine, Tongji Hospital,

Tongji Medical College, Huazhong University of Science and Technology,

and Hubei Key Laboratory of Genetics and Molecular Mechanisms of

Cardiological Disorders, Wuhan 430030, China

${ }^{2}$ Hubei Key Laboratory of Genetics and Molecular Mechanism of

Cardiological Disorders, Huazhong University of Science and Technology,

Wuhan, China
}

(c) The Author(s). 2019 Open Access This article is distributed under the terms of the Creative Commons Attribution 4.0 International License (http://creativecommons.org/licenses/by/4.0/), which permits unrestricted use, distribution, and reproduction in any medium, provided you give appropriate credit to the original author(s) and the source, provide a link to the Creative Commons license, and indicate if changes were made. The Creative Commons Public Domain Dedication waiver (http://creativecommons.org/publicdomain/zero/1.0/) applies to the data made available in this article, unless otherwise stated. 


\section{Background}

Lung carcinoma is the most common cancer worldwide, with 1.8 million newly diagnosed patients per year, and has a higher mortality than that of the next top three cancers combined (158,080 vs 115,760 deaths/year) [1,2]. While some treatments, such as radiation and immunotherapy, have given hope to lung cancer patients over the past few decades [3], its 5 -year survival rate remains very poor [4]. That said, anti-angiogenesis treatments and the eradication and functional inhibition of tumour-associated endothelial cells (ECs), have emerged as important cancer treatments $[5,6]$. However, the outcomes of current antiangiogenic therapies that primarily target vascular endothelial growth factor (VEGF) pathways depend on cancer types and stages, and often lead to the development of resistance, hypertension, proteinuria, or even death [7]. Thus, more effective and safer antiangiogenic therapies require further investigation.

Arachidonic acid (AA) released from membrane phospholipids is converted into various bioactive lipid mediators, such as epoxyeicosatrienoic acids (EETs), prostaglandins (PGs), and hydroxyeicosatetraenoic acids (HETEs), by either cytochrome P450 (CYP) epoxygenases, cyclooxygenase (COX), or lipoxygenase (LOX) pathways [8, 9]. Among them, EETs are particularly powerful pro-angiogenic eicosanoids and are positively linked with cancer progression $[10$, 11]. Cyp2c44, the functional homologue of human Cyp2c9, is one of the main CYP epoxygenases for EET biosynthesis in endothelial cells $[12,13]$. Disruption of the Cyp2c44 gene, or downregulation of its expression, reduces endothelial proliferation and tubular morphogenesis in vitro and inhibits primary tumour growth in vivo $[12,13]$. Taken together, the Cyp2c44-EETs axis may be a vital target for cancer treatment, including lung cancer.

Peroxisome proliferator-activated nuclear receptor alpha $(P P A R \alpha)$ is a ligand-activated nuclear receptor that modulates the transcription of specific target genes implicated in lipid metabolism and energy homeostasis [14, 15]. The PPAR $\alpha$-mediated transcriptional regulation of the Cyp $2 c 44$ gene has been clearly established in previous studies $[12,16]$. Once activated, PPAR $\alpha$ translocates into the nucleus, and then binds to the PPAR response element (PPRE) in the promotor of the Cyp2c44 gene and reduces its expression, thereby indicating why PPAR $\alpha$ agonists inhibit angiogenic activity and tumour vascularization [12, 13]. Unfortunately, application of traditional PPAR $\alpha$ agonists were restricted due its insufficient efficacy and hepatotoxicity [17].

As previously reported, AVE8134 is a specific and highaffinity ligand for PPAR $\alpha$, and shares with Wyeth-14,643 its PPARa selectivity and ability to improve plasma lipid profiles in rodents $[18,19]$. More importantly, AVE8134 has been used in humans and has shown to be well tolerated at doses between 10 and $20 \mathrm{mg} / \mathrm{kg}$ body weight per day in contrast with Wyeth $[18,19]$. We assume that, as with Wyeth, AVE8134 downregulates Cyp2c44 expression in the host endothelium, causing a decrease in the production of pro-angiogenic eicosanoid EETs and the inhibition of tumour vascularization, growth, and metastasis. We are proposing to repurpose AVE8134 as a safe agent for the treatment of human cancers.

\section{Methods \\ Reagents}

The Lipofectamine 2000 reagent was obtained from Invitrogen (Life Technologies Corporation, Carlsbad, CA). The primers for Cyp2C9 siRNA, and their controls were purchased from RiboBio (Guangzhou, China). The PPAR $\alpha$ ligand AVE8134, 2-Methyl-6-(\{3-[(2-phenyl-1,3oxazol-4-yl)methoxy]propoxy\}methyl) benzoic acid, were synthesized by Dr. John R. Falck and kindly offered by Jorge H. Capdevila from the Department of Medicine (Division of Nephrology), Vanderbilt University, Nashville, USA. Wyeth-14,643, Bezafibrate, the PPAR $\alpha$ antagonist GW6471, and the COX inhibitor indomethacin were purchased from MedChemExpress (New Jersey, USA). 11-HETE and four kinds of EETs were purchased from Cayman Chemical (Ann Arbor, Michigan, USA). For the purchasing information on some of the other conventional reagents in our lab, please refer to our previous articles $[15,20,21]$.

\section{Cell culture}

TC-1 tumour cells (\#341334), originating from lung epithelial cells from C57BL/6 mice, were purchased from BeNa culture Collection (Sunzhou, China) and grown in RPMI 1640 medium supplemented with 10\% fetal bovine serum (FBS) (Gibco, Grand Island, USA), $100 \mathrm{U} / \mathrm{mL}$ streptomycin, and $100 \mathrm{U} / \mathrm{mL}$ penicillin [22]. B16F10 melanoma cells (\#TCM36) were obtained from the Cell Bank at the Chinese Academy of Science (Shanghai, China) and were maintained in Dulbecco's Modified Eagle Medium (DMEM) with the aforementioned supplements [23]. Cells were grown in a humidified atmosphere of $95 \%$ air and $5 \% \mathrm{CO}_{2}$ at $37^{\circ} \mathrm{C}$ and harvested by $0.25 \%$ trypsin containing EDTA. The harvested cells were then used for tumour implantation. Human umbilical vein endothelial cells (HUVECs) (\#CRL-1730) were obtained from American Type Tissue Collection (ATCC) and cultured in RPMI-1640 supplemented with $10 \%$ FBS [20]. For protein analysis or cell proliferation, cells were plated in 6-well and 96-well plates and treated by different concentrations of AVE8134, 11-HETE, or GW6471 for $48 \mathrm{~h}$. Before plating for migration or angiogenesis experiments, HUVECs were first treated with AVE8134 for $48 \mathrm{~h}$ or 11-HETE for $24 \mathrm{~h}$. 


\section{Animal experiments}

Wild-type C57BL/6 mice (10-12 weeks old) used for in vivo experiments were purchased from the Model Animal Research Center of Nanjing University (Nanjing, China). Cyp2c44-/- mice were kindly provided by Artiom Gruzdev, Ph.D. (NIH/NIEHS) [13] and bred in the specific pathogen-free animal centre of Tongji Medical College. All the animals were maintained under 12$\mathrm{h}$ light/12-h dark photoperiods with free access to water and food [21]. Tumour-bearing mice were established by subcutaneously injecting $1 \times 10^{6}$ TC- 1 cells or B16F10 cells in $50 \mu \mathrm{l}$ phosphate-buffered saline (PBS) containing $50 \mu \mathrm{l}$ Matrigel (BD Pharmingen) into the shaved left flank as previously described $[13,16]$. Mice were considered tumour bearing when tumours became palpable at about 7-10 days after the first injection. Subsequently, the mice were divided into different treatment groups and this was considered the day 0 time point. Tumour growth was measured with a caliper using the formula $\mathrm{V}=\mathrm{W}^{2} \mathrm{~L} \pi / 6$, where $\mathrm{V}$ is the mean tumour volume, $\mathrm{W}$ is the mean short diameter, and $\mathrm{L}$ is the mean long diameter, and mice were humanely euthanized with an intraperitoneal injection of pentobarbital sodium $(150 \mathrm{mg} / \mathrm{kg}$ ) when tumours exceeded $20 \mathrm{~mm}$ in "L" diameter [23].

\section{Experiment 1}

TC-1 tumour-bearing mice were randomly divided into four groups according to the initial tumour sizes: (i) The equivalent concentration of dimethylsulfoxide (DMSO) was dissolved in drinking water as a control; (ii) $0.025 \%$ (g/ml) AVE8134 in the drinking water [19]; (iii) $0.025 \%$ (g/ml) Wyeth-14,643 in the drinking water [13]; (iv) $0.3 \%(\mathrm{~g} / \mathrm{ml})$ Bezafibrate in the drinking water [13]. Before being adjusted to the designated concentration in the drinking water, all PPAR $\alpha$ ligands were solubilized by DMSO. The drinking water was changed every week.

\section{Experiment 2}

TC-1 or B16F10 tumour-bearing mice were treated with or without 11-HETE at a rate of $15 \mu \mathrm{g} / \mathrm{kg} /$ day by an osmotic mini-pump as previously described [21].

\section{Experiment 3}

Cyp $2 c 44^{-1-}$ mice and littermate controls were induced into tumour-bearing, and then treated with or without 0.025\% (g/ml) AVE8134 [19].

\section{Experiment 4}

TC-1 or B16F10 tumour-bearing mice were randomly divided into four groups: (i) the equivalent concentration of DMSO was dissolved in drinking water as a control; (ii) $0.01 \%(\mathrm{~g} / \mathrm{ml})$ indomethacin (COX inhibitor) alone in the drinking water [24]; (iii) $0.025 \%(\mathrm{~g} / \mathrm{ml})$ AVE8134 alone in the drinking water; (iv) $0.01 \%$ indomethacin and AVE8134 in the drinking water.

\section{Gene silencing}

HUVEC cells were transfected with either siRNA against human Cyp2c9 (100 nM) or a negative control (100 nM) siRNA using the Lipofectamine 2000 reagent according to the manufacturer's protocol [21]. The medium was changed $4 \mathrm{~h}$ later and the cells continued to be cultured for an additional $48 \mathrm{~h}$.

\section{Cells proliferation and migration}

Endothelial cell proliferation was measured by bromodeoxyuridine (BrdU) incorporation assay using a BrdU Cell Proliferation Elisa Kit (Exalpha Biologicals, Inc., Massachusetts, CA, USA), according to the manufacturer's instructions. In detail, HUVEC cells were cultured in 96-well plates at a density of $1 \times 10^{4}$ cells/ well in the presence or absence of AVE8134, EETs, or 11-HETE. Subsequently, the $1 \times$ BrdU Reagent was added to the wells for the final $2 \mathrm{~h}$. Cells were fixed and permeabilized with Fixative/Denaturing Solution, and then incubated with an anti-BrdU detector antibody provided in the kit. The coloured reaction product was quantified using a spectrophotometer at a wavelength of $450 \mathrm{~nm}$. Eight micrometre Boyden chambers (CostarCorning, New York, USA) were used to detect cell migration according to our established assay [23, 25]. Briefly, pretreated or transfected HUVEC cells $\left(1 \times 10^{5}\right)$ were placed in the upper chamber with serum-free medium, while the lower chamber was filled with $200 \mu \mathrm{l}$ of complete medium. The cells were allowed to migrate at $37^{\circ} \mathrm{C}$ for $8 \mathrm{~h}$, after which the non-traversed cells in the upper side were removed by cotton swabs, and the cells in the lower side were fixed with $4 \%$ paraformaldehyde and stained with crystal violet (Beyotime, Nantong, China) for $30 \mathrm{~min}$. The stained cells were then counted under an optical microscope (Nikon, Tokyo, Japan).

\section{In vitro angiogenesis assay}

For the Matrigel-based tubulogenesis assay, capillary-like structure formation was analysed as previously described [16]. Briefly, 96-well plates were pre-coated with $50 \mu \mathrm{l}$ Matrigel (BD Biosciences, San Jose, CA, USA) for $30 \mathrm{~min}$ at $37^{\circ} \mathrm{C}$. After being stimulated by AVE8134 for $48 \mathrm{~h}$ or 11-HETE for $24 \mathrm{~h}, 1 \times 10^{5}$ HUVEC cells were seeded into each well and cultured for another $4 \mathrm{~h}$. The formation of capillary-like structures was then photographed, and the number of capillary-like structures was counted. The tube length was analysed by the AxioVision Rel software version 4.8 (Carl Zeiss AG, Jena, Germany). 
Liquid chromatography-tandem mass spectrometry (LCMS/MS)

The metabolites in the cell lysates and tissues from mice were measured by LC-MS/MS (ACQUITY UPLC) in the laboratory of Prof. Yi Zhu at Tianjin Medical University as they previously described [26]. Briefly, $100 \mathrm{mg}$ of tumour tissues, livers, or lungs were homogenized before lipid extraction. HUVECs were lysed by repeated freeze-thawing cycles and then pre-processed in methanol. After centrifugation, the supernatant was extracted by ethyl acetate twice, and then the upper organic phase was evaporated. The residue was then dissolved in $100 \mu \mathrm{l} \mathrm{30 \%}$ acetonitrile. The resulting sample was then subjected to ultra-high-performance liquid chromatography (Waters, Milford, MA) with a 5500 QTRAP hybrid triplequadruple linear ion trap mass spectrometer (AB Sciex, Foster City, USA) equipped with a Turbo Ion Spray electrospray ionization source.

\section{Western blot and quantitative real-time (qRT)-PCR}

Proteins within tumour tissues and HUVEC cells were extracted using a Boster Kit (Bosterbio, CA, USA) according to the manufacturer's instructions. Western blotting was performed as previously described [20]. The antibody, which was raised against the Cyp2c44's IGRHQPPSMKDKMKC peptide (GenScript), was generated according to previous studies $[13,16]$. Other antibodies used in this study are as follows: Glyceraldehyde 3-phosphate dehydrogenase (GAPDH) (Bosterbio), $\beta$ actin (Bosterbio), Cyp2c9 (Abcam, Cambridge, UK), COX1 (Santa Cruz, CA, USA), COX2 (Santa Cruz), Phosphorylated extracellular signal-regulated kinase $1 / 2$ (p-ERK1/2) (Santa Cruz), ERK1/2 (Santa Cruz), P-AKT (Abcam), AKT (Abcam), and CD31 (Abcam).

For qRT-PCR, RNA from tumours was extracted using TRIzol (Invitrogen, Carlsbad, CA, USA) according to the manufacturer's instructions and reversetranscribed using the M-MLV First-Strand cDNA Synthesis Kit (Invitrogen) [15]. The mRNA levels of target genes were quantified by qRT-PCR using Power SYBR Green PCR Master Mix (Invitrogen) with the primers listed in Additional file 1: Table S1. GAPDH served as an internal control and the results were analysed using the $2^{-\Delta \Delta \mathrm{Ct}}$ method.

\section{Histology and Immunohistochemical staining}

Tumours and lung tissues were fixed in $4 \%$ paraformaldehyde and processed for histology or immunohistochemistry. For vascular density assessment, an FITC-conjugated CD31 antibody was used to label vascular endothelial cells and the percentage of CD31-positive structures/microscopic field was evaluated by Scion Imaging Software (Frederick, MD) [13].
The numbers of metastatic tumours in the lungs were assessed by hematoxylin-eosin (HE) staining as previously described [13].

\section{Detection of plasma lipid content and alanine aminotransferase (ALT)}

The plasma triglyceride (TG) content was determined by colorimetric assays according to the product manual of a TG assay kit (Jiancheng bio, Nanjing, China) [15]. Briefly, plasma samples were extracted by the addition of 2:1 chloroform/methanol. The dried organic phase was then re-suspended in $100 \%$ ethanol and analysed using an enzymatic colorimetric method (GPO-PAP reagent, Rohe Diagnostics). The level of serum ALT was detected by an ALT assay Kit (Jiancheng bio).

\section{COX activity assay}

COX Activity was analysed by a COX Activity Assay Kit (Cayman chem, Ann Arbor, MI). To determine COX2 activity, SC-560 was added into the reaction wells to eliminate all COX-1 activity.

\section{Statistical analysis}

Data are presented as means \pm SEM. The numbers of repetitions and groups are listed in the figure legends. Statistical analysis was based on a one-way ANOVA with a Tukey's post hoc test; $P<0.05$ was considered statistically significant.

\section{Result}

The novel PPARa ligand AVE8134 affected tumour growth and metastasis differently as compared to Wyeth14,643 and Bezafibrate

AVE8134 is a new synthetic PPAR $\alpha$ agonist that has excited many researchers given its anti-angiogenesis and anti-tumour properties, as well as its high PPAR $\alpha$ affinity and low hepatotoxicity $[18,19]$. However, whether it has any advantages in the treatment of cancer in comparison to other traditional PPAR $\alpha$ agonists is still unknown. Thus, we compared AVE8134 with Wyeth-14,643 and Bezafibrate in TC-1 tumour-bearing mice. Although the concentration of plasma TGs and the expression of acylCoA thioesterase 1 (Acot1), a downstream target gene of PPAR $\alpha$, were affected equally when mice were treated with the three PPAR $\alpha$ agonists (Fig. 1a and b), these ligands showed different actions on tumour suppression and AA metabolism. As shown in Fig. 1c, after a 22 day treatment, AVE8134 inhibited TC-1 tumour sizes more than the untreated control group, but its effect were weaker than Wyeth-14,643 and stronger than Bezafibrate. As for metastasis, only Wyeth-14,643 significantly reduced pulmonary metastasis, as assessed by the weight of the lungs and HE staining (Fig. 1d and e). However, Wyeth- 


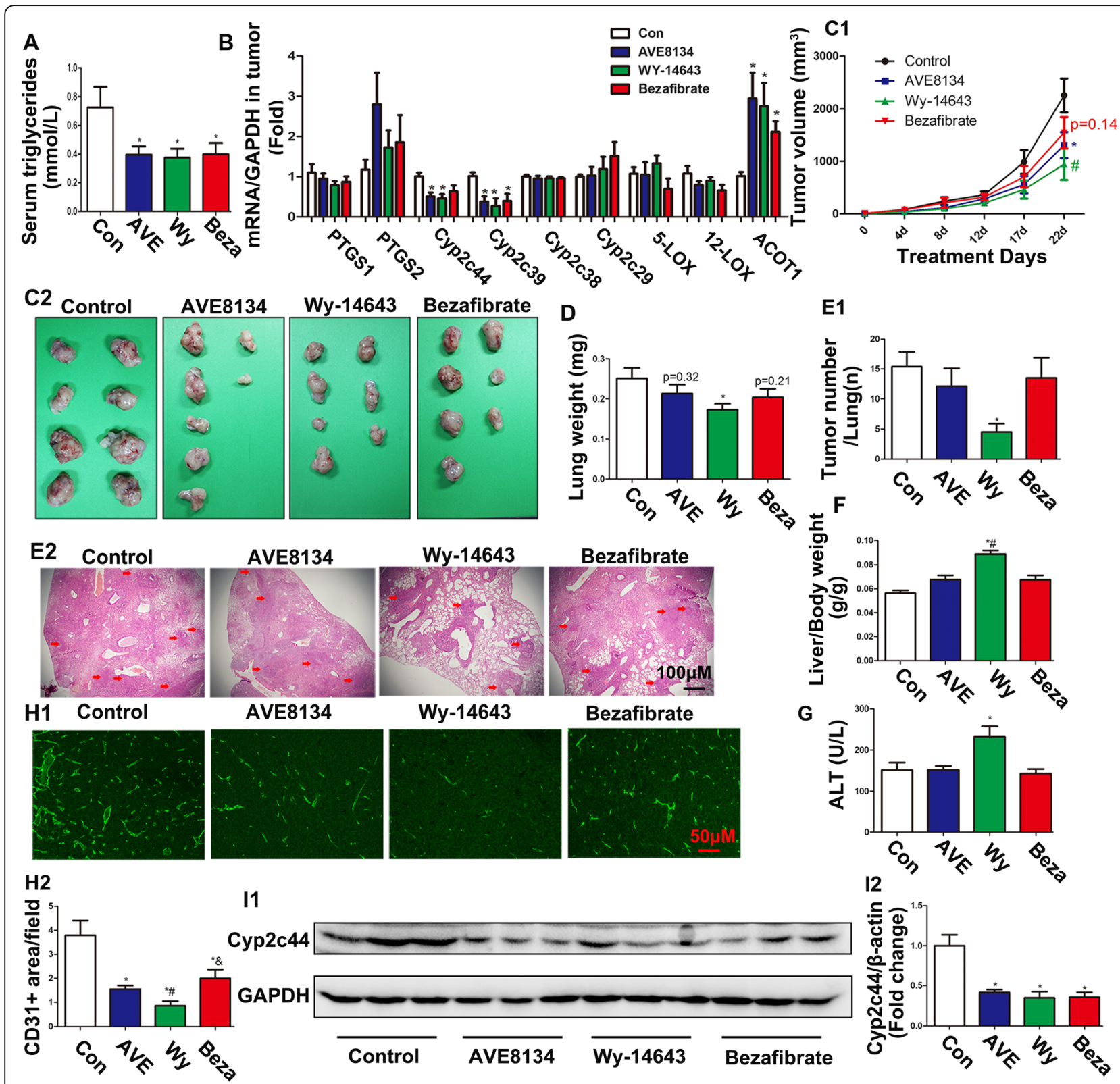

Fig. 1 Different PPARa ligands exhibited different abilities to inhibit tumour sizes and metastasis. a Serum triglyceride levels in TC-1 tumour-bearing mice $(n=6-11)$. ${ }^{*} P<0.05$, vs control. b Relative mRNA levels of Ptgs1 (Cox1), Ptgs2 (Cox2), Cyp2c44, Cyp2c39, Cyp2c38, Cyp2c29, Alox5, Alox12, Acot1 $(n=6) .{ }^{*} P<0.05$, vs control. $\mathbf{c 1}$ and $\mathbf{c 2}$ Images of the primary xenograft tumours and their growth curves in mice treated with three different PPARa ligands, AVE8134 (AVE), Wy-14,643 (Wy), and Bezafibrate (Beza; $n=8-11$ ). " $P<0.05$, AVE vs control; ${ }^{\#} P<0.05$, Wy vs control. $\mathbf{d}$ The weight of lungs in TC-1 tumour-bearing mice $(n=8-11) .{ }^{*} P<0.05$, vs control. e1 and e2 Hematoxylin and eosin (HE) staining and the number of lung metastatic tumours (red arrowhead; $n=8-11$ ). ${ }^{*} P<0.05$, vs control. $\mathbf{f}$ The ratio of liver weight to body weight $(n=8-11)$. ${ }^{*} P<0.05$, vs control; ${ }^{*} P<0.05$, vs AVE. g The levels of serum ALT $(n=6) .{ }^{*} P<0.05$, vs control. h1 and h2 Tumour vascularization was quantified by CD31 antibodies in the paraffin sections of primary xenograft tumours. ${ }^{*} P<0.05$, vs control; ${ }^{\#} P<0.05$ vs AVE; ${ }^{\&} P<0.05$ vs Wy. (11 and 12) Representative bands of Cyp2c44 and GAPDH in tumours were evaluated by western blot. ${ }^{*} P<0.05$, vs control $(n \geq 3)$

14,643 showed the strongest effects on hepatomegaly as compared to the other two PPAR $\alpha$ agonists (Fig. 1f). AVE8134 failed to increase the level of serum ALT as Wyeth-14,643 did, indicating its advantages with respect to liver injury (Fig. 1g).
PPARa agonists inhibited the expression of Cyp2c44 and the density of tumour vascular

Previous studies have reported that the levels of Cyp2c44 expression and EET biosynthesis, which are positively associated with tumour growth and angiogenesis, were 
controlled by PPAR $\alpha$ activation in the endothelium [12, 13, 16]. The vessel density in tumours, as determined by anti-CD31 staining, was significantly inhibited by PPAR $\alpha$ activation, with the strongest inhibition being observed for Wyeth-14,643, followed by AVE8134 and then Bezafibrate (Fig. 1h). Thus, we then detected the expression of four main Cyp2c subunits, Cyp2c29, 38, 39, and 44, in TC-1-bearing tumours. As shown in Fig. $1 \mathrm{~b}$ and i, all three PPAR $\alpha$ agonists decreased Cyp2c38 and Cyp2c44 expression in tumours.

\section{PPARa agonists altered the metabolites of AA}

Eicosanoids, including EETs, PGs, and HETEs, are a series of bioactive lipid molecules metabolized from arachidonic acid (AA) via three primary enzymatic pathways, COX, lipoxygenase (LOX) and cytochrome P450s (CYP), or in a nonenzymatic manner [8, 27]. AA-derived EETs are closely associated with tumour angiogenesis and development $[11,27]$. Thus, we analysed 31 AAderived metabolites in tumours, livers, and lungs from tumour-bearing mice by LC - MS/MS. Among them, six eicosanoids (including LXA4, 16-HETE, 17-HETE, 18HETE, 19-HETE, 20-HETE) were undetectable in some samples and excluded. Changes in the other 25 eicosanoids are shown in the heat maps within Fig. 2a. Briefly, AVE8134 significantly reduced 13 eicosanoids (EETs, DHETs, PGB2, PGJ2, etc.), but increased two products (11-HETE and 15-HETE) in tumours (Fig. 2b-d). Most of these eicosanoids were also regulated by Wyeth-14, 643 and Bezafibrate. Similar trends for most of these eicosanoids were observed in both lung and liver samples (Fig. 2e and f). Among them, EETs and 11-HETE were the most interesting, with EETs being a vital factor for tumour angiogenesis and 11-HETE being the only increased eicosanoid in all PPAR $\alpha$ agonist-treated groups and tissues. AVE8134 showed weaker inhibition on EETs and DHETs than Wyeth-14,643 but stronger inhibition than Bezafibrate (Fig. 2b and c). As expected, the concentration of EETs in tumours was positively correlated with tumour size (Fig. 2g). The 11-HETE increased most in Wyeth-14,643-treated group, followed by AVE8134and Bezafibrate-treated groups (Fig. 2d).

\section{AVE8134 inhibited endothelial proliferation, tube formation, and migration by activating PPARa}

HUVECs were used to validate the effects of AVE8134 on angiogenesis in vitro. AVE8134 significantly inhibited endothelial cell proliferation, tube formation, and migration when the final concentration reached $1 \mu \mathrm{M}$ (Fig. $3 a-c)$, but its inhibitory action did not increase when the concentration increased. AVE8134's inhibitory action was blocked by PPAR $\alpha$ receptor antagonist GW6471 (Fig. 3b-d). Moreover, AVE8134 treatment significantly downregulated the expression of Cyp2c9 (the functional homologue of Cyp2c44 in mice) in HUVECs, which was also reversed by GW6471 (Fig. 3e and f).

\section{1-HETE promoted endothelial proliferation and angiogenesis, causing tumour growth and lung metastasis}

We observed that 11-HETE was significantly increased in each PPAR $\alpha$ treatment group, but its biological function was still unclear. In our in vivo experiments we found that increased 11-HETE significantly promoted the growth of TC-1 tumours (Fig. 4a). Moreover, lung metastasis and tumour angiogenesis in the 11-HETE treatment group significantly increased compared with the control group (Fig. 4b-d). In another tumour model, 11-HETE also promoted the growth of B16F10 melanoma cells (Fig. 4e). Thus, we concluded that 11-HETE promoted tumour growth, similar to EETs, and did not affect EET biosynthesis (Fig. 4f and g). In addition, we further revealed the effects of 11-HETE on endothelial function in vitro. As shown in Fig. 4h-j, 11-HETE promoted endothelial proliferation, cell migration, and tube formation in a dose-dependent manner. This may be related to its activation of the AKT/ERK1/2 proliferation signalling pathways (Fig. 4k and $\mathrm{l}$ ).

\section{The increased 11-HETE partly counteracted the benefits of reduced EETs caused by PPARa activation on tumour treatment}

As noted above, we found that PPAR $\alpha$ reduced EET biosynthesis but increased the concentration of 11-HETE. Given that these are two opposite effects, we speculated that the inhibitory effect of PPAR $\alpha$ agonists on tumour growth and angiogenesis depended on both EETs and 11-HETE levels (Fig. 5a). We used the value of $\triangle$ EETs $\triangle 11$-HETE as a resultant vector and found that there was a negative linear correlation between $\triangle E E T s-\Delta 11$ HETE and tumour size (Fig. 5b). Subsequently, Cyp2c44 knockout $(\mathrm{KO})$ mice were used to interdict the production of EETs. As shown in Fig. 5c-e, Cyp2c44 KO significantly reduced EET production but did not affect 11 HETE levels in TC-1 tumours, which led to a decrease in tumour size. Opposite to this effect in WT tumourbearing mice, AVE8134 treatment increased tumour sizes in $\mathrm{KO}$ tumour-bearing mice compared with the KO controls (Fig. 5c). This may be because AVE8134 did not decrease the level of EETs in KO tumourbearing mice, but increased the 11-HETE level instead (Fig. $5 \mathrm{~d}$ and e). Our in vitro experiments showed that silencing Cyp2c9 alone or AVE8134 treatment alone significantly reduced the proliferation, migration, and tubular formation of endothelial cells (Fig. 5f-h). However, in the endothelium with low Cyp2c9 expression, the inhibitory effects of AVE8134 were reversed, which 


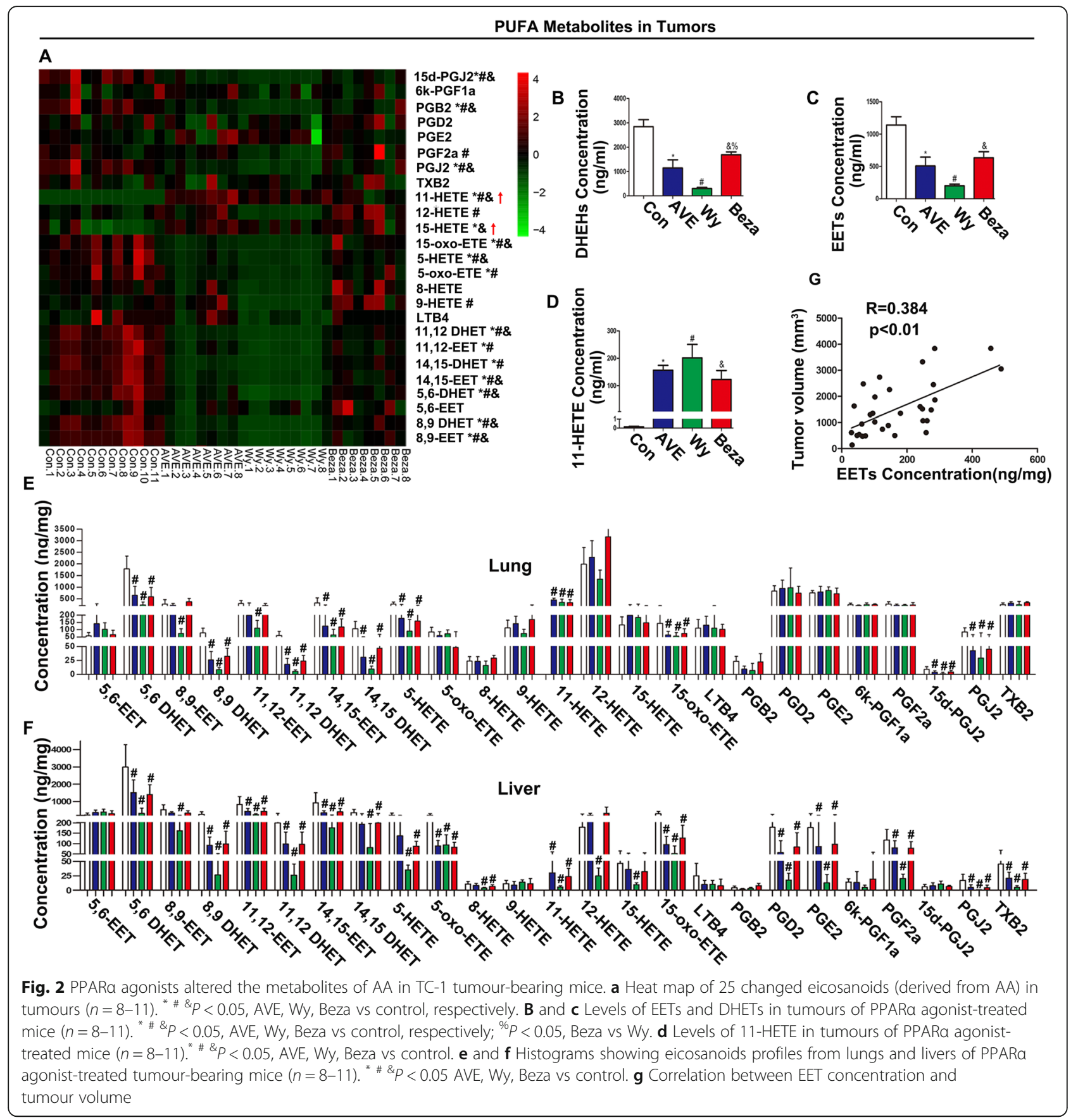

was closely associated with the increased production of 11-HETE (Fig. 5i and j).

The COX $1 / 2$ inhibitor indomethacin enhanced the antitumour effects of AVE8134

Although the main products of COX1 and COX2 are prostaglandins, these enzymes also convert AA to 11HpETE, which is subsequently converted by the peroxidase activity to the corresponding 11-HETE [8, 28]. Previous studies have found that the COX inhibitor indomethacin reduced the formation of 11-HETE in bovine coronary artery endothelial cells $[24,29,30]$ and that aspirin-acetylated $\mathrm{COX}$ was also responsible for the inhibition of 11-HETE production [31]. Although the expression of COX1 and COX2 was not changed in HUVECs, AVE8134 may have changed their catalytic structure (Fig. 6a). This was confirmed by the fact that AVE8134 shifted the COX1 activity to COX2 activity in tumours (Fig. 6b). Thus, we combined indomethacin with AVE8134 in an attempt to find a better therapeutic 


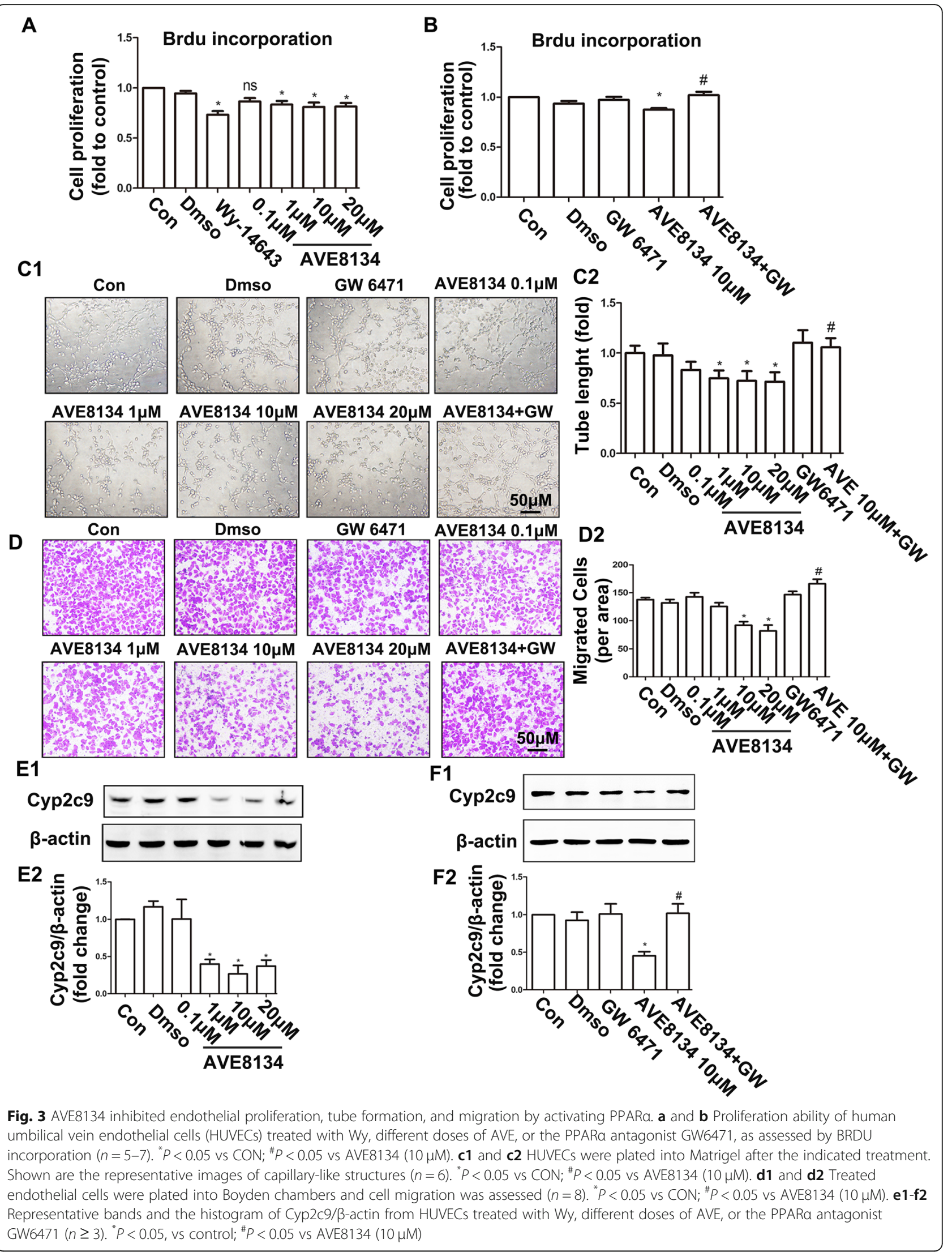




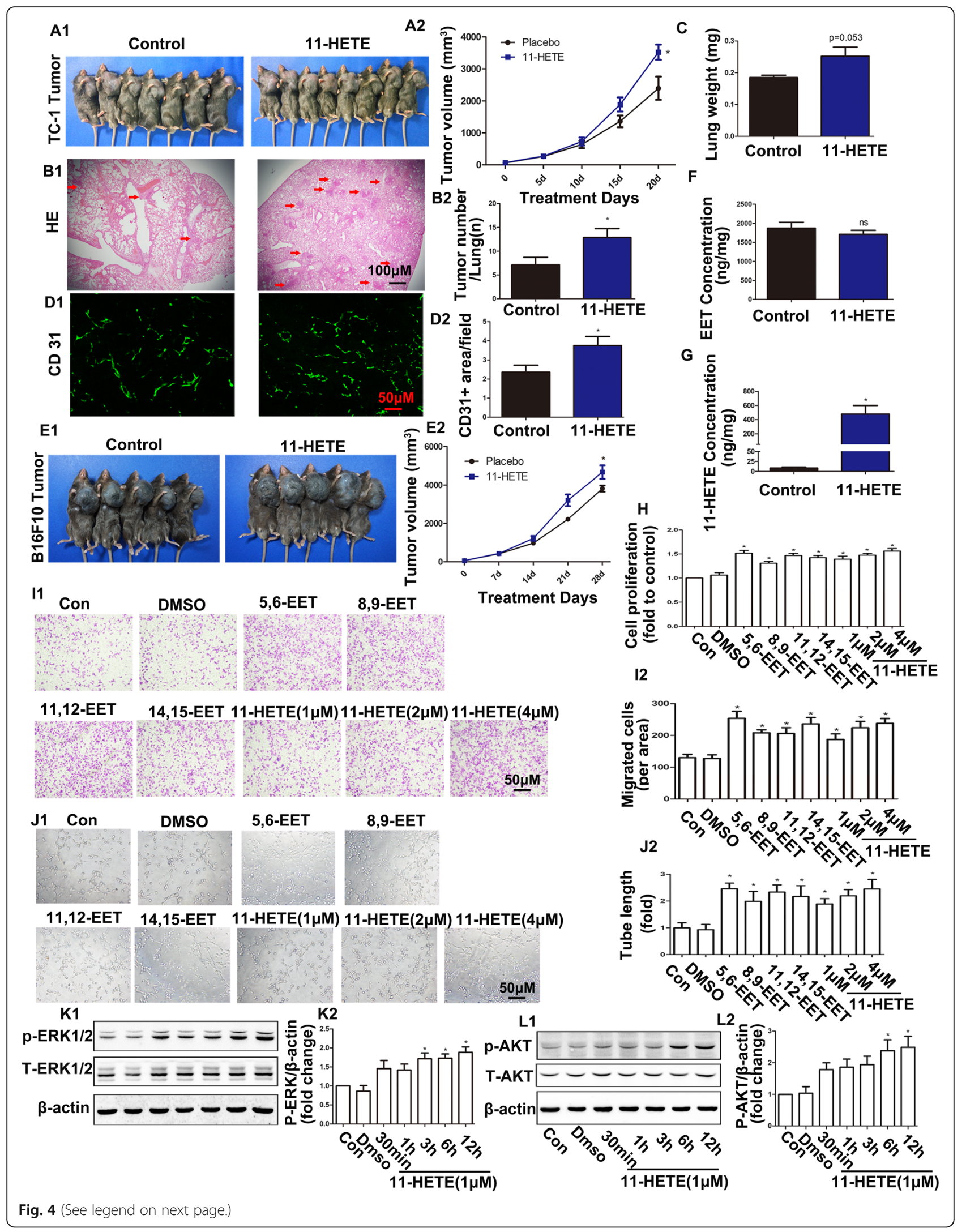


(See figure on previous page.)

Fig. 4 11-HETE promoted endothelial proliferation and angiogenesis, causing tumour growth and lung metastasis. a1 and a2 Images of TC-1 primary xenograft tumours and their growth curves in mice treated with or without 11-HETE $(n=8) .{ }^{*} P<0.05$ vs control. b1 and b2 Hematoxylin and eosin (HE) staining and the number of lung metastatic tumours (red arrowhead; $n=8$ ). ${ }^{*} P<0.05$ vs control. c The weight of lungs in TC- 1 tumour-bearing mice $(n=8)$. ${ }^{*} P<0.05$ vs control. $\mathbf{d} 1$ and $\mathbf{d} 2$ Tumour vascularization was quantified by CD31 antibodies in paraffin sections of TC1 primary xenograft tumours $(n=8) .{ }^{*} P<0.05$ vs control. $\mathbf{e} 1$ and $\mathbf{e} 2$ Images of B16F10 primary xenograft tumours and their growth curves in mice treated with or without 11-HETE $(n=8)$. ${ }^{*} P<0.05$ vs control. $\mathbf{f}$ and $\mathbf{g}$ Levels of EETs and 11-HETE in TC-1 tumours of treated mice. ${ }^{*} P<0.05$ vs control. $\mathbf{h}$ Proliferative ability of HUVECs treated with EETs and different doses of 11-HETE, as assessed by BrdU incorporation $(n=4)$. ${ }^{*} P<0.05$ vs. control. i1 and i2 Representative images of migrated cells at the indicated treatment $(n=10) .{ }^{*} P<0.05$, vs control. $\mathbf{j} \mathbf{1}$ and $\mathbf{j} \mathbf{2}$ Representative images of capillary-like structures at the indicated treatment $(n=7)$. ${ }^{*} P<0.05$ vs control. $\mathbf{k} 1-\mathbf{1 2}$ Western blot showing the activation of the AKT and ERK pathways under 11 -HETE stimulation $(n \geq 3) .{ }^{*} P<0.05$ vs control

effect against tumours. Indomethacin failed to decrease the size of TC-1 tumours but significantly enhanced the inhibitory actions of AVE8134 (Fig. 6c) without causing liver damage (Fig. 6d). This may be because indomethacin blocked the increase in 11-HETE caused by AVE8134 (Fig. 6e and f). Moreover, the expression of CD31 was further inhibited by the addition of indomethacin as compared to the AVE8134 treatment alone (Fig. 6g). In the B16F10 melanoma model, indomethacin also synergistically inhibited tumour growth and and lung metastasis with AVE8134 (Fig. 7a-b). Similarly, AVE8134 treatment combined with indomethacin showed stronger inhibition of the proliferation, migration, and tubular formation of endothelial cells compared with either treatment alone (Fig. 7c-e).

In conclusion, we found that there were significantly differences in the effects of different PPAR $\alpha$ ligands on tumour sizes and metastasis. Although AVE8134 was less beneficial with respect to tumour sizes and metastasis than Wyeth-14,643, it was much safer. Except for their inhibitory action on the Cyp2c44-EETs axis, the PPAR $\alpha$ ligands also augmented the formation of 11HETE. The increased 11-HETE promoted angiogenesis and tumour growth, counteracting the beneficial effects of the PPAR $\alpha$ ligands. Indomethacin, a COX inhibitor, decreased 11-HETE, enhancing the anti-angiogenesis and anti-tumour effects of AVE8134. Thus, AVE8134 combined with indomethacin may have therapeutic potential against cancer, including lung cancer.

\section{Discussion}

In this study, we proposed that AVE8134 acts as a novel anti-angiogenic drug that could be effective in the treatment of cancers. This is based on the fact that AVE8134 is a high affinity ligand for PPAR $\alpha$ and is well tolerated in humans. Unfortunately, AVE8134 was not the strongest anti-tumorigenic and anti-angiogenic drug when compared with two other PPAR $\alpha$ ligands and even failed to control lung metastasis. Metabolomics analysis found that PPAR $\alpha$ ligands not only decreased EET biosynthesis by downregulating Cyp2c44 expression but also increased the production of a pro-angiogenic factor, 11HETE, which in return counteracted their benefits on tumour suppression. That is, the effect of PPAR $\alpha$ ligands on tumour inhibition depended on the variation in EETs and 11-HETE (DEETs- $\triangle 11$-HETE). Moreover, we found that the COX inhibitor indomethacin optimized the therapeutic effects of AVE8134 on tumour growth and angiogenesis via decreasing the formation of 11-HETE. Taken together, these results suggest that AVE8134 is an attractive drug for treating cancer if combined with indomethacin.

Angiogenesis is not only an important mechanism by which tumours obtain sufficient nutritional support and remove metabolic waste, but it is also required for the growth of numerous solid tumours and their metastases [32, 33]. Tumours remain in a dormant state until they become vascularized and these immature vessels increase the chance of tumour cells entering circulation and immigrating to distant organs [32, 34]. Angiogenesis is a complex multi-step process, involving endothelial cell proliferation, migration, sprouting, and transforming into tube-like structures [35]. A variety of endogenous factors, such as vascular endothelial growth factor (VEGF), basic fibroblast growth factors (bFGF), epidermal growth factor (EGF) and EETs, promote angiogenesis and contribute to the development of tumours. This makes these factors ideal targets for cancer treatments $[36,37]$. CYP epoxygenases and their metabolites, EETs, are upregulated in human tumours and have been identified as powerful pro-angiogenetic mediators [23, 38]. Overexpression of CYP epoxygenases or inhibiting EET hydrolysis by soluble epoxide hydrolase inhibitors ( $\mathrm{sEHi}$ ) demonstrated their capacity to promote tumour growth and metastasis in many preclinical studies [23, 34]. CYP epoxygenase inhibitors will hopefully enter into clinical trials for cancer treatments [23, 39]. PPAR $\alpha$ agonists exhibited a reduction in tumour growth and vascularization by suppressing Cyp2c44 expression, which connects them with clinical tumor treatment $[12,13,16]$.

PPARs are members of the steroid receptor superfamily and there are three subtypes: PPAR $-\alpha,-\delta$, and $-\gamma$. These receptors are important ligand-activated transcription factors involved in the regulation of cell proliferation and energy metabolism [15, 40]. Interestingly, 


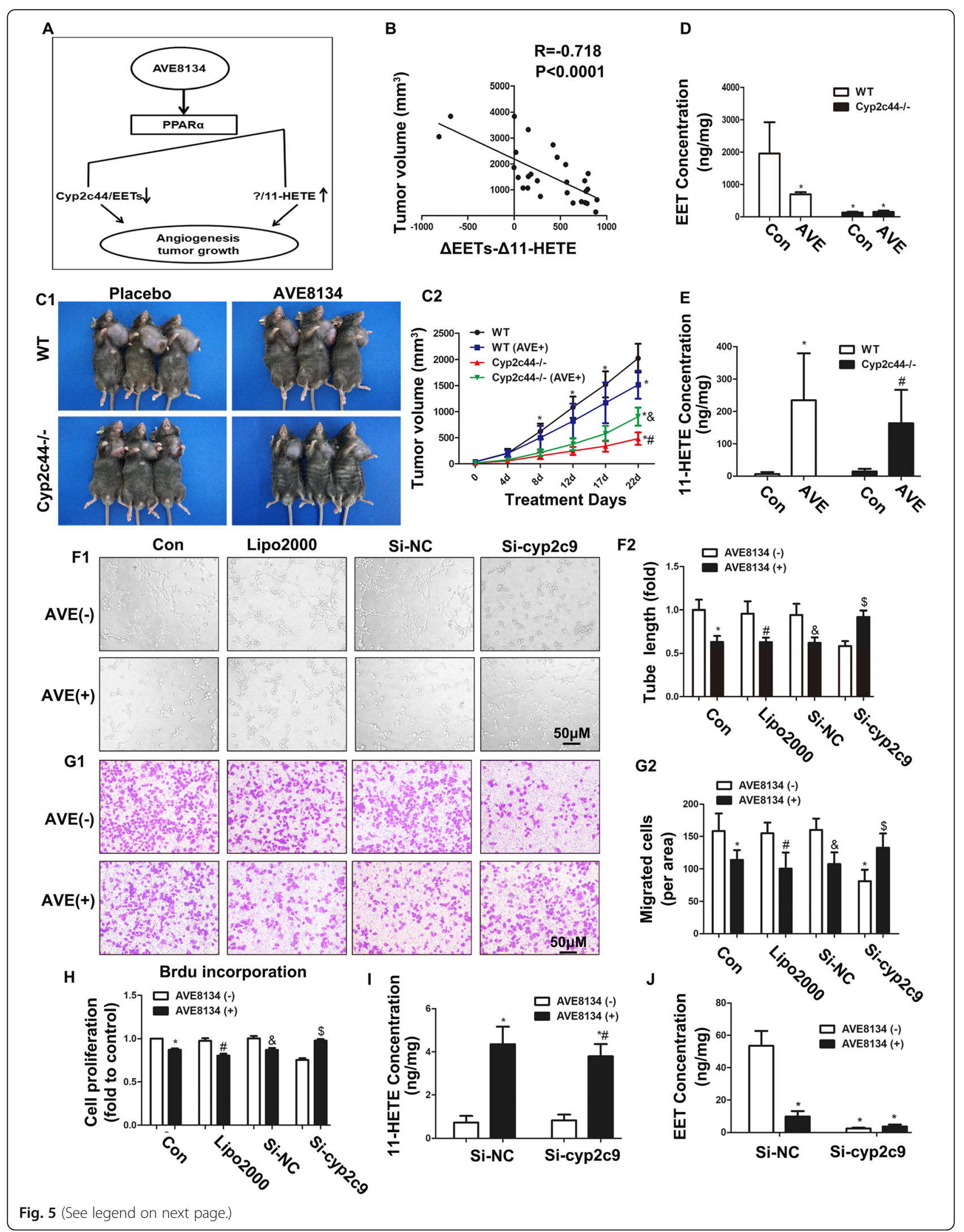


(See figure on previous page.)

Fig. 5 The increased 11-HETE counteracted the benefits from reduced EETs caused by PPARa activation on tumour treatment. a A schematic diagram showing the relationship between EETs and 11-HETE and how it is regulated by AVE8134. b $\Delta$ EETs and $\Delta 11$-HETE represents the difference between EETs and 11-HETE between PPARa ligand-treated groups and the control group. Shown is the correlation between $\Delta$ EETs - $\Delta 11-\mathrm{HETE}$ concentration and tumour volume. $\mathbf{c 1}$ and $\mathbf{c 2}$ Images of TC-1 primary xenograft tumours and their growth curves in WT and Cyp2c44 ${ }^{-1-}$ mice treated with or without AVE8134 ( $n=6-7) .{ }^{*} P<0.05$ vs WT placebo group; ${ }^{*} P<0.05$ vs WT AVE group; ${ }^{\circledR} P<0.05$ vs Cyp2c44 ${ }^{-/-}$placebo group. $\mathbf{d}$ and $\mathbf{e}$ Levels of EETs and 11-HETE in TC-1 tumours ( $n=6-7) .{ }^{*} P<0.05$ vs WT placebo group; ${ }^{*} P<0.05$ vs Cyp2c44-1- placebo group. f1-g2 Representative images of capillary-like structures and cell migration at the indicated treatment and their histograms $(n=7)$. ${ }^{*} P<0.05$ vs control; ${ }^{*} P<0.05$ vs lipo2000; ${ }^{\circledR} P<0.05$ vs si-nc; ${ }^{\$} P<0.05$ vs si-Cyp2c9. (H) Proliferative ability of HUVECs transfected with Cyp2C9 siRNA and then treated with or without AVE8134, as assessed by BrdU incorporation $(n=4) .{ }^{*} P<0.05$ vs control; ${ }^{~} P<0.05$ vs lipo2000; ${ }^{\circledR} P<0.05$ vs si-nc; ${ }^{\$} P<0.05$ vs si-Cyp2c9. $\mathbf{i}$ and $\mathbf{j}$ Levels of EETs and $11-\mathrm{HETE}$ in HUVECs transfected Cyp2C9 siRNA and then treated with or without AVE8134 $(n=5) .{ }^{*} \mathrm{P}<0.05$ vs si-nc; ${ }^{\#} P<0.05$ vs si-Cyp2c9

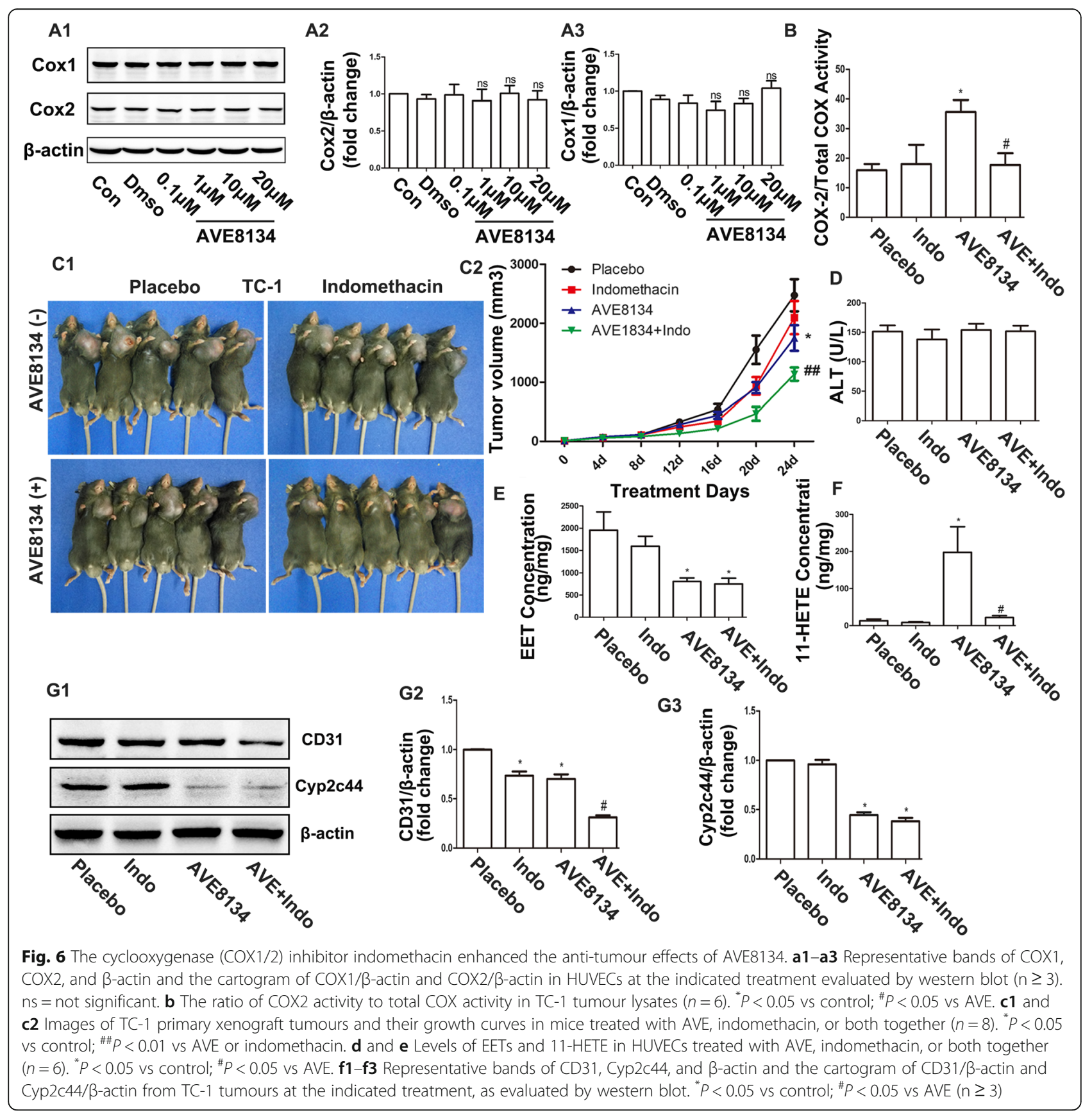




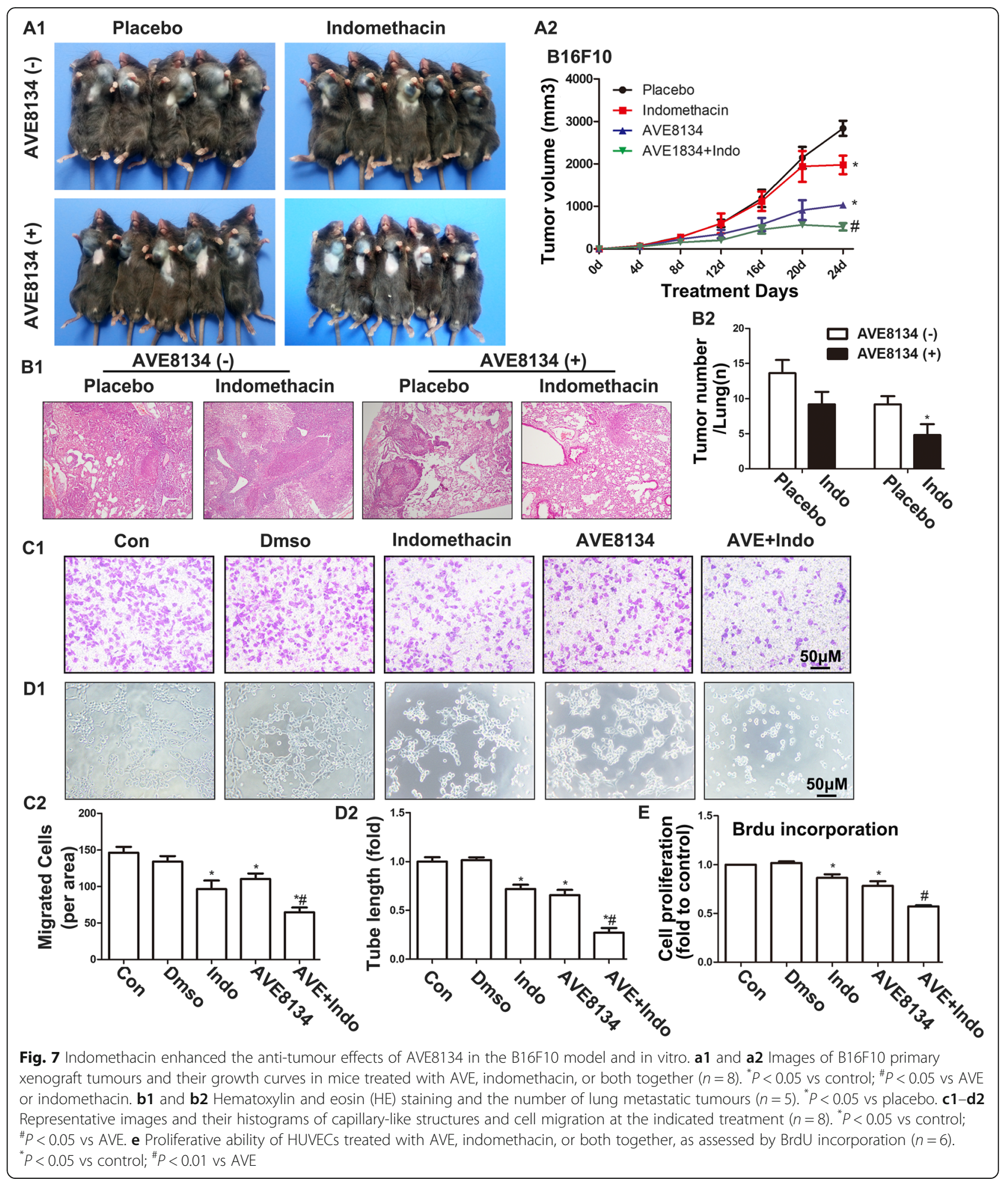

increasing evidence has showed that PPAR activation exhibited multiple functions in tumour progression [41]. Compared with the unified conclusion that PPAR $\gamma$ inhibited the growth of various tumours [42], the effects of PPAR $\alpha$ on tumour progression were diverse and depended on the tissue type or PPAR $\alpha$ ligands [13]. In some studies, PPAR $\alpha$ deficiency inhibited tumorigenesis through increasing the endogenous angiogenesis inhibitor thrombospondin-1 (TSP-1) [43]. Moreover, PPAR $\alpha$ activation enhances breast cancer cell proliferation by 
upregulating cyclin E levels [44]. Conversely, PPAR $\alpha$ activation with Wyeth-14,643 or fenofibrate was also reported to inhibit endothelial cell growth and non-small cell lung cancer (NSCLC) progression via binding to the PPER area in the promoter of mouse Cyp2c44 [12, 13, 16]. Besides the paradoxical roles of PPAR $\alpha$, another nonnegligible issue impeding its use in clinical trials is that PPAR $\alpha$ agonists typically increase the incidence of liver hepatomegaly and tumours through induction of cell proliferation and oxidative stress [17]. This study compared the effects of three different PPAR $\alpha$ agonists on tumour progression and liver hepatomegaly and found that the novel PPAR $\alpha$ ligand AVE8134 was an ideal choice for tumour treatment given its effectiveness and safety. Inconsistent with previous studies, this study suggests that PPAR $\alpha$ ligands not only reduce EET production via downregulating Cyp2c44 expression but also increase 11-HETE biosynthesis. Increased 11-HETE was shown to be a pro-angiogenic and -tumorigenic factor, which partially cancelled out the benefits from decreased EETs in tumour-bearing mice. Thus, the combined utilization of drugs that inhibit 11-HETE formation may solve this issue and enhance the anti-tumour effect of AVE8134.

11-HETE, a bioactive metabolite derived from AA, is mainly generated from COX enzymes, while LOX and CYP enzymes, and non-enzymatic catalytic pathways may also contributed to its production [30,31]. Previous research has reported that the COX2 specific inhibitor, celecoxib, reduced 11-HETE production in lung cancer A549 cells [45]. AA can bind to the COX active site in a specific catalytic arrangement that leads to 11-HETE production, which is inhibited by aspirin treatment [29, 46]. Moreover, the non-specific COX inhibitor indomethacin was observed to reduce the formation of 11HETE in bovine coronary artery endothelial cells [29, 30]. These results suggest that the formation of 11HETE relies on COX enzymes. Although increased 11HETE is described as a biomarker ranging from coronary events to cancers, its biological function remains unclear [47]. This study found that 11-HETE stimulated endothelial proliferation, migration, and angiogenesis, as well as the subsequent growth and metastasis of tumours.

Although the control region of the COX2 gene possesses one response element for PPAR (PPRE), there is no evidence that indicates that PPAR $\alpha$ activation affects its expression [48]. However, a previous study has reported that PPAR $\gamma$ activation participates in the transcriptional activation of the COX2 gene [49]. That said, PPAR $\alpha$ may change the catalytic arrangement at the COX active site. This may be important given the fact that COX-2 is an inducible isoform of COXs and its overexpression is linked to various cancers [50]. Both
COX1 and COX2 inhibitors have been reported to inhibit tumour progression and this inhibition underlies their anti-inflammation and anti-angiogenesis effects $[51,52]$. The COX inhibitor indomethacin has been used previously as a non-steroidal anti-inflammatory drug for the treatment of various inflammatory diseases, such as arthritis, fever, and various headache syndromes [53]. In subsequent preclinical and clinical studies, researchers found that indomethacin exhibits anti-tumour activity [52], although the underlying mechanisms are unclear. This study found that indomethacin synergistically strengthened the anti-tumour effects of AVE8134 by inhibiting the production of 11-HETE. Although indomethacin alone inhibited the activation of endothelial cells and slightly suppressed the growth of TC-1 lung tumours, its joint effects with AVE8134 seem more powerful. Thus, combining the novel PPAR $\alpha$ ligand AVE8134 with the COX inhibitor indomethacin provides a new and effective strategy for the treatment of cancer.

\section{Conclusions}

In this study, we revealed that PPAR $\alpha$ ligands were able to change the levels of AA-derived metabolites. The novel PPAR $\alpha$ agonist AVE8134 showed advantages at security in tumor treatment, although its anti-tumor effect was inferior to wyeth-14,643. Except for the well-known downregulation of CYP2c44 expression and subsequent EET synthesis, AVE8134 significantly increased the levels of 11-HETE, possibly through changing the catalytic activity of COX enzymes. Increased 11-HETE facilitates angiogenesis and tumour progression, which was effectively blocked by the COX inhibitor indomethacin. The combined treatment of indomethacin with AVE8134 may be an ideal and effective drug combination for the treatment of cancer, including lung cancer.

\section{Supplementary information}

Supplementary information accompanies this paper at https://doi.org/10. 1186/s12885-019-6379-5.

Additional file 1. Primers For qRT-PCR.
Abbreviations

11-HETE: 11-Hydroxyeicosatetraenoic acids; AA: Arachidonic acid; AVE8134: 2Methyl-6-(\{3-[(2-phenyl-1,3-oxazol-4-yl)methoxy]propoxy\}methyl) benzoic acid; bFGF: Basic fibroblast growth factors; BrdU: Bromodeoxyuridine; COX: Cyclooxygenase; CYP: Cytochrome P450; EETs: Epoxyeicosatrienoic acids; EGF: Epidermal growth factor; ERK: Extracellular signal-regulated kinase; HETEs: Hydroxyeicosatetraenoic acids; HUVECs: Human umbilical vein endothelial cells; LC: Lung cancer; LC-MS/MS: Liquid chromatographytandem mass spectrometry; LOX: Lipoxygenase; NSCLC: Non-small-cell lung cancer; PGs: Prostaglandins; PPARs: Peroxisome proliferator-activated receptors; PPARa: Peroxisome proliferator-activated nuclear receptor alpha; PPRE: PPAR response element; sEHi: Soluble epoxide hydrolase inhibitors; VEGF: Vascular endothelial growth factor 


\section{Acknowledgments}

We thank Jorge H. Capdevila and John R. Falck for kindly providing the PPARa ligand AVE8134, Artiom Gruzdev for kindly providing the Cyp2c44 mice and Xu Zhang for contributing to the mass spectrometry analysis.

\section{Authors' contributions}

These studies were conceived and suggested to DWW by Dr. John R. Falck and Jorge H. Capdevila during one of their visits to Wuhan in 2014. LW conceived and performed the experiments, collected and analyzed data, and wrote the manuscript. WW, MD, HHL conducted parts of the animal experiments and collected the data. CC and DW agreed with the study and reviewed and edited the manuscript. All authors have read and approved the manuscript.

\section{Funding}

This work was supported by grants from National Nature Science Foundation of China (NSFC) (No. 81500292, No. 81471021 and No. 81900244). The funding body had no role in the design of the study and collection, analysis, and interpretation of data and in writing the manuscript.

\section{Availability of data and materials}

The authors declare that materials described in the manuscript, including all relevant raw data, will be available from the corresponding author upon reasonable request.

\section{Ethics approval}

All experiments were performed with the approval of the Animal Research Committee of Tongji Medical College, Huazhong University of Science and Technology, and in accordance with ARRIVE and NIH guidelines for animal welfare.

\section{Consent for publication}

Not applicable.

\section{Competing interests}

The authors declare that they have no competing interests.

Received: 23 April 2019 Accepted: 19 November 2019

Published online: 02 December 2019

\section{References}

1. Siegel RL, Miller KD, Jemal A. Cancer statistics, 2017. CA Cancer J Clin. 2017; 67(1):7-30.

2. Duruisseaux M, Esteller M. Lung cancer epigenetics: from knowledge to applications. Semin Cancer Biol. 2018;51:116-28.

3. Reck M, Rabe KF. Precision diagnosis and treatment for advanced nonsmall-cell lung Cancer. N Engl J Med. 2017:377(9):849-61.

4. Tsao AS, Scagliotti GV, Bunn PA Jr, Carbone DP, Warren GW, Bai C, de Koning HJ, Yousaf-Khan AU, McWilliams A, Tsao MS, et al. Scientific advances in lung Cancer 2015. J Thorac Oncol. 2016;11(5):613-38.

5. Bikfalvi A, Bicknell R. Recent advances in angiogenesis, anti-angiogenesis and vascular targeting. Trends Pharmacol Sci. 2002;23(12):576-82.

6. van Hinsbergh WW, Collen A, Koolwijk P. Angiogenesis and antiangiogenesis: perspectives for the treatment of solid tumors. Ann Oncol. 1999;10(Suppl 4):60-3.

7. Carmeliet P, Jain RK. Principles and mechanisms of vessel normalization for cancer and other angiogenic diseases. Nat Rev Drug Discov. 2011; 10(6):417-27.

8. Xu X, Li R, Chen G, Hoopes SL, Zeldin DC, Wang DW. The Role of Cytochrome P450 Epoxygenases, Soluble Epoxide Hydrolase, and Epoxyeicosatrienoic Acids in Metabolic Diseases. Adv Nutr. 2016;7(6): $1122-8$.

9. Harizi H, Corcuff JB, Gualde N. Arachidonic-acid-derived eicosanoids: roles in biology and immunopathology. Trends Mol Med. 2008;14(10):461-9.

10. Chen C, Wang DW. Cytochrome P450-CYP2 Family-Epoxygenase Role in Inflammation and Cancer. Adv Pharmacol. 2015;74:193-221.

11. Panigrahy D, Greene ER, Pozzi A, Wang DW, Zeldin DC. EET signaling in cancer. Cancer Metastasis Rev. 2011;30(3-4):525-40.

12. Pozzi A, Popescu V, Yang S, Mei S, Shi M, Puolitaival SM, Caprioli RM, Capdevila JH. The anti-tumorigenic properties of peroxisomal proliferator- activated receptor alpha are arachidonic acid epoxygenase-mediated. J Biol Chem. 2010:285(17):12840-50.

13. Skrypnyk N, Chen X, Hu W, Su Y, Mont S, Yang S, Gangadhariah M, Wei S, Falck JR, Jat JL, et al. PPARalpha activation can help prevent and treat nonsmall cell lung cancer. Cancer Res. 2014;74(2):621-31.

14. Bougarne N, Weyers B, Desmet SJ, Deckers J, Ray DW, Staels B, De Bosscher K. Molecular actions of PPARalpha in lipid metabolism and inflammation. Endocr Rev. 2018;39(5):760-802.

15. Wu L, Wang K, Wang W, Wen Z, Wang P, Liu L, Wang DW. Glucagon-like peptide-1 ameliorates cardiac lipotoxicity in diabetic cardiomyopathy via the PPARa pathway. Aging Cell. 2018;17:e12763.

16. Pozzi A, Ibanez MR, Gatica AE, Yang S, Wei S, Mei S, Falck JR, Capdevila JH, Peroxisomal proliferator-activated receptor-alpha-dependent inhibition of endothelial cell proliferation and tumorigenesis. J Biol Chem. 2007;282(24): 17685-95.

17. Hedrington MS, Davis SN. Peroxisome proliferator-activated receptor alphamediated drug toxicity in the liver. Expert Opin Drug Metab Toxicol. 2018; 14(7):671-7.

18. Linz W, Wohlfart P, Baader M, Breitschopf K, Falk E, Schafer HL, Gerl M, Kramer W, Rutten $\mathrm{H}$. The peroxisome proliferator-activated receptoralpha (PPAR-alpha) agonist, AVE8134, attenuates the progression of heart failure and increases survival in rats. Acta Pharmacol Sin. 2009; 30(7):935-46.

19. Schafer HL, Linz W, Falk E, Glien M, Glombik H, Korn M, Wendler W, Herling AW, Rutten H. AVE8134, a novel potent PPARalpha agonist, improves lipid profile and glucose metabolism in dyslipidemic mice and type 2 diabetic rats. Acta Pharmacol Sin. 2012;33(1):82-90.

20. Wu L, Zhao F, Dai M, Li H, Chen C, Nie J, Wang P, Wang DW. P2y12 Receptor Promotes Pressure Overload-Induced Cardiac Remodeling via Platelet-Driven Inflammation in Mice. Hypertension. 2017;70(4):759-69.

21. Dai M, Wu L, Wang P, Wen Z, Xu X, Wang DW. CYP2J2 and its metabolites EETs attenuate insulin resistance via regulating macrophage polarization in adipose tissue. Sci Rep. 2017;7:46743.

22. Loeser S, Loser K, Bijker MS, Rangachari M, van der Burg SH, Wada T, Beissert $\mathrm{S}$, Melief CJ, Penninger JM. Spontaneous tumor rejection by cbl-b-deficient CD8+ T cells. J Exp Med. 2007;204(4):879-91.

23. Jiang JG, Ning YG, Chen C, Ma D, Liu ZJ, Yang S, Zhou J, Xiao X, Zhang XA, Edin ML, et al. Cytochrome p450 epoxygenase promotes human cancer metastasis. Cancer Res. 2007;67(14):6665-74.

24. Revtyak GE, Hughes MJ, Johnson AR, Campbell WB. Histamine stimulation of prostaglandin and HETE synthesis in human endothelial cells. Am J Phys. 1988;255(2 Pt 1):C214-25.

25. Dai M, Wu L, He Z, Zhang S, Chen C, Xu X, Wang P, Gruzdev A, Zeldin $D C$, Wang DW. Epoxyeicosatrienoic acids regulate macrophage polarization and prevent LPS-induced cardiac dysfunction. J Cell Physiol. 2015;230(9):2108-19.

26. Zhang X, Yang N, Ai D, Zhu Y. Systematic metabolomic analysis of eicosanoids after omega-3 polyunsaturated fatty acid supplementation by a highly specific liquid chromatography-tandem mass spectrometry-based method. J Proteome Res. 2015;14(4):1843-53.

27. Chen C, Wang DW. CYP epoxygenase derived EETs. From cardiovascular protection to human cancer therapy. Curr Top Med Chem. 2013;13(12): 1454-69.

28. Patrignani P, Patrono C. Aspirin and Cancer. J Am Coll Cardiol. 2016;68(9):967-76.

29. Lopez S, Vila L, Breviario F, de Castellarnau C. Interleukin-1 increases 15hydroxyeicosatetraenoic acid formation in cultured human endothelial cells. Biochim Biophys Acta. 1993;1170(1):17-24.

30. Setty BN, Stuart MJ, Walenga RW. Formation of 11-hydroxyeicosatetraenoic acid and 15-hydroxyeicosatetraenoic acid in human umbilical arteries is catalyzed by cyclooxygenase. Biochim Biophys Acta. 1985;833(3):484-94.

31. Bailey JM, Bryant RW, Whiting J, Salata K. Characterization of 11-HETE and 15-HETE, together with prostacyclin, as major products of the cyclooxygenase pathway in cultured rat aorta smooth muscle cells. J Lipid Res. 1983;24(11):1419-28.

32. Li T, Kang G, Wang T, Huang H. Tumor angiogenesis and anti-angiogenic gene therapy for cancer. Oncol Lett. 2018;16(1):687-702.

33. Mander KA, Finnie JW. Tumour angiogenesis, anti-angiogenic therapy and chemotherapeutic resistance. Aust Vet J. 2018;96(10):371-8.

34. Sausville LN, Williams SM, Pozzi A. Cytochrome P450 epoxygenases and cancer: a genetic and a molecular perspective. Pharmacol Ther. 2019; 196:183-94. 
35. Jeong HW, Hernandez-Rodriguez B. Transcriptional regulation of endothelial cell behavior during sprouting angiogenesis. 2017, 8(1):726.

36. Wang Z, Dabrosin C, Yin X, Fuster MM, Arreola A, Rathmell WK, Generali D, Nagaraju GP, El-Rayes B, Ribatti D, et al. Broad targeting of angiogenesis for cancer prevention and therapy. Semin Cancer Biol. 2015;35(Suppl):S224-s243.

37. Albini A, Tosetti F, Li WW, Noonan DM, Li WW. Cancer prevention by targeting angiogenesis. Nat Rev Clin Oncol. 2012;9(9):498-509.

38. Chen C, Wei X, Rao X, Wu J, Yang S, Chen F, Ma D, Zhou J, Dackor RT, Zeldin DC, et al. Cytochrome P450 2J2 is highly expressed in hematologic malignant diseases and promotes tumor cell growth. J Pharmacol Exp Ther. 2011;336(2):344-55.

39. Geldenhuys WJ, Khayat MT, Yun J, Nayeem MA. Drug delivery and Nanoformulations for the cardiovascular system. Res Rev Drug Deliv. 2017; 1(1):32-40.

40. Dubois V, Eeckhoute J, Lefebvre P, Staels B. Distinct but complementary contributions of PPAR isotypes to energy homeostasis. J Clin Invest. 2017; 127(4):1202-14.

41. Antonosante A, d'Angelo M, Castelli V, Catanesi M, lannotta D, Giordano A, Ippoliti R, Benedetti E. The Involvement of PPARs in the Peculiar Energetic Metabolism of Tumor Cells. Int J Mol Sci. 2018;19(7). https://doi.org/10.3390/ ijms19071907.

42. Grommes C, Landreth GE, Heneka MT. Antineoplastic effects of peroxisome proliferator-activated receptor gamma agonists. Lancet Oncol. 2004;5(7):419-29.

43. Panigrahy D, Kaipainen A, Huang S, Butterfield CE, Barnes CM, Fannon M, Laforme AM, Chaponis DM, Folkman J, Kieran MW. PPARalpha agonist fenofibrate suppresses tumor growth through direct and indirect angiogenesis inhibition. Proc Natl Acad Sci U S A. 2008;105(3):985-90.

44. Chang NW, Wu CT, Chen DR, Yeh CY, Lin C. High levels of arachidonic acid and peroxisome proliferator-activated receptor-alpha in breast cancer tissues are associated with promoting cancer cell proliferation. J Nutr Biochem. 2013;24(1):274-81.

45. Kempen EC, Yang P, Felix E, Madden T, Newman RA. Simultaneous quantification of arachidonic acid metabolites in cultured tumor cells using highperformance liquid chromatography/electrospray ionization tandem mass spectrometry. Anal Biochem. 2001;297(2):183-90.

46. Rowlinson SW, Crews BC, Goodwin DC, Schneider C, Gierse JK, Marnett L. Spatial requirements for 15-(R)-hydroxy-5Z,8Z,11Z, 13E-eicosatetraenoic acid synthesis within the cyclooxygenase active site of murine COX-2. Why acetylated COX-1 does not synthesize 15-(R)-hete. J Biol Chem. 2000;275(9): 6586-91.

47. Pickens CA, Sordillo LM, Zhang C, Fenton Jl. Obesity is positively associated with arachidonic acid-derived 5- and 11-hydroxyeicosatetraenoic acid (HETE). Metab Clin Exp. 2017;70:177-91.

48. Kang YJ, Mbonye UR, DeLong CJ, Wada M, Smith WL. Regulation of intracellular cyclooxygenase levels by gene transcription and protein degradation. Prog Lipid Res. 2007:46(2):108-25.

49. Ackerman $W E$, Zhang $X L$, Rovin BH, Kniss DA. Modulation of cytokine-induced cyclooxygenase 2 expression by PPARG ligands through NFkappaB signal disruption in human WISH and amnion cells. Biol Reprod. 2005;73(3):527-35.

50. Gasparini G, Longo R, Sarmiento R, Morabito A. Inhibitors of cyclo-oxygenase 2: a new class of anticancer agents? Lancet Oncol. 2003;4(10):605-15.

51. Baron JA, Sandler RS. Nonsteroidal anti-inflammatory drugs and cancer prevention. Annu Rev Med. 2000;51:511-23.

52. Wang D, Dubois RN. Prostaglandins and cancer. Gut. 2006;55(1):115-22.

53. Gotzsche PC. Patients' preference in indomethacin trials. an overview. Lancet. 1989;1(8629):88-91.

\section{Publisher's Note}

Springer Nature remains neutral with regard to jurisdictional claims in published maps and institutional affiliations.

Ready to submit your research? Choose BMC and benefit from:

- fast, convenient online submission

- thorough peer review by experienced researchers in your field

- rapid publication on acceptance

- support for research data, including large and complex data types

- gold Open Access which fosters wider collaboration and increased citations

- maximum visibility for your research: over $100 \mathrm{M}$ website views per year

At BMC, research is always in progress.

Learn more biomedcentral.com/submissions 